\title{
AS ATRIBUIÇÕES DO TÉCNICO DE SAÚDE BUCAL: SISTEMATIZAÇÃO DE PRÁTICAS
}

\author{
THE ATTRIBUTIONS OF THE ORAL HEALTH TECHNICIAN: PRACTICE SYSTEMATIZATION
}

\author{
Eliana Maria de Oliveira Sá ${ }^{1}$ \\ Marilene Barros de Melo ${ }^{2}$ \\ Carlos Alberto Tenório Cavalcanti ${ }^{3}$ \\ Lucas Azevedo de Oliveira $^{4}$ \\ Nora Nei Reis Pereira ${ }^{5}$ \\ Onofre Ricardo de Almeida Marques ${ }^{6}$ \\ Rubens de Menezes Santos ${ }^{7}$ \\ Dulce Helena Amaral Gonçalves ${ }^{8}$
}

Resumo Diante da necessidade de diretrizes para a atuação clínica do técnico de saúde bucal (TSB), anterior à lei $n .{ }^{\circ} 11.889 / 2008$, que regulamentou a sua prática profissional, realizou-se em 2008 uma pesquisa-ação em 12 centros de saúde, com 350 usuários, 22 TSB e 22 cirurgiões-dentistas. Teve como objetivo sistematizar as atribuições dos TSB no município de Belo Horizonte. Tratou-se de um estudo de natureza qualitativa, a partir de entrevista, grupo focal, oficina e observação participante. A técnica de análise de conteúdo foi utilizada para exame minucioso das informações, das quais apreenderam-se as seguintes categorias: fundamentação da prática e padronização das ações; valorização profissional e estratégias de resistência; avanços e desafios; e modalidade de pesquisa-ação. A transformação do espaço laboral em local de aprendizagem possibilitou avanços como cooperação e corresponsabilização. Uma boa supervisão do cirurgião-dentista propiciou qualidade às atribuições executadas pelo TSB, mesmo no tratamento restaurador atraumático.

Palavras-chave técnico em saúde bucal; pesquisaação; formação em serviço.
Abstract Given the need for guidelines for oral health technicians (OHT) to undertake their activities, prior to Act 11889/2008, which regulated this category's professional practice, a research-action was carried out in 2008 at 12 health centers and involved 350 users, 22 OHTs, and 22 dentists. The goal was to systematize the OHTs' attributions in the city of Belo Horizonte. This was a qualitative study, based on interviews, focus groups, workshops, and participant observation. The content analysis technique was used to carefully examine the information, and the following categories were gathered based on it: practice substantiation and action standardization; professional appreciation and resistance strategies; progress made and challenges; and research-action mode. Transforming the work place into a place of learning allowed for advances such as cooperation and co-responsibility. Good supervision by the dentist has provided quality to the work done by the OHTs, even in the atraumatic restorative treatment.

Keywords oral health technician; research-action; in-service training. 


\section{Introdução}

Diante da larga extensão territorial, da densidade populacional do Brasil e da carta de princípios que rege o Sistema Único de Saúde (SUS), algumas estratégias têm sido criadas para garantir a qualidade das ações da saúde a todos os cidadãos. Entre elas, a estruturação de equipes de trabalho integradas por profissionais de nível superior, técnico e auxiliar em saúde.

No âmbito da odontologia, alguns profissionais, como os antigos auxiliares de consultório dentário (ACD) e técnicos em higiene dental (THD) trabalham dando suporte direto ao cirurgião-dentista durante o atendimento clínico. A atuação profissional do ACD e do THD foi legitimada pela resolução do CFO n. ${ }^{\circ}$ 185/1993, alterada pela de n. ${ }^{\circ}$ 209/1997. Em 21 de outubro de 2003 foi homologado o seu perfil de competências, pelo Ministério da Saúde (MS), por intermédio da Secretaria de Gestão do Trabalho e da Educação na Saúde (SGTES) e da Coordenação Nacional de Saúde Bucal (CNSB), em consenso com o Conselho Nacional de Secretários de Saúde (Conass), Conselho Nacional de Secretários Municipais de Saúde (Conasems), Conselho Federal de Odontologia (CFO), Associação Brasileira de Odontologia (ABO), Associação Brasileira de Ensino Odontológico (Abeno), Federação Interestadual dos Odontologistas (FIO), Federação Nacional dos Odontologistas (FNO), Associação Nacional de Auxiliares e Técnicos de Odontologia (Anato) e todos os outros atores sociais envolvidos com o trabalho do ACD e THD. Esse perfil foi publicado em 2004 (Brasil, 2004a) e ampliado pela Política Nacional de Saúde Bucal, o 'Brasil Sorridente' (Brasil, 2004b). Em 24/12/2008, a lei n. ${ }^{\circ} 11.889$ (Brasil, 2008) regulamentou a ação desses profissionais. Essa lei restringe a ação do THD e o renomeia para técnico em saúde bucal (TSB), enquanto que o ACD passou a ser designado como auxiliar em saúde bucal (ASB). Neste artigo, por se referir cronologicamente a uma investigação anterior à lei, usaremos a antiga terminologia de THD.

Até então, esses trabalhadores tinham a ação profissional orientada pela Política Nacional de Saúde Bucal, o 'Brasil Sorridente' (Brasil, 2004b). Apesar de esta política nortear o perfil de competências dessas ocupações, observava-se, no âmbito do processo de atenção em saúde bucal da Secretaria Municipal de Saúde de Belo Horizonte (SMSA-BH), uma diversidade de ações na prática do THD. Diante desse contexto, vários questionamentos surgiram relacionados ao exercício da função e à forma como se processava o trabalho do THD e a supervisão do cirurgião-dentista (CD).

Na tentativa de abrir espaços para esse tipo de discussão, a Coordenação de Saúde Bucal da SMSA-BH apresentou ao Conselho Municipal de Saúde o 'Projeto Global de Saúde Bucal', no primeiro semestre de 2006. Nesse documento, foram aprovados os compromissos mínimos assumidos para a atenção básica, a proposta de organização dos outros níveis de assistência e 
a descrição das metas de gestão. Para honrar estes compromissos foi necessário um conjunto de medidas estruturantes, entre elas a busca de novas evidências na prática profissional do THD. Era necessário definir uma padronização de condutas no trabalho deste profissional, inclusive sobre o desenvolvimento de atividades de recuperação da saúde - tratamento restaurador atraumático (ART).

Para legitimar e conferir credibilidade à definição das atribuições do THD, a coordenação de saúde bucal do município verificou a necessidade de realizar uma pesquisa. O objetivo era buscar novos argumentos científicos que permitissem sistematizar as práticas desta categoria profissional. A pesquisa poderia subsidiar a decisão da Coordenação de Saúde Bucal da SMSA-BH sobre a elaboração de diretrizes relativas à atuação clínica do THD na rede municipal, incluindo ou não sua participação em atividades restauradoras.

Este artigo se propõe a socializar os resultados da pesquisa Buscando novas evidências na prática clínica do técnico em saúde bucal, aprovada pelo Comitê de Ética da SMSA-BH por meio do parecer n. ${ }^{\circ}$ 049/2007. Foi desenvolvida junto aos profissionais de saúde bucal da rede do SUS de Belo Horizonte (SUS-BH), no período de fevereiro de 2007 a dezembro de 2008. Para tal, buscou-se um referencial teórico e uma metodologia adequados aos propósitos desta pesquisa. O aporte de teoria fundamentou-se, assim, no referencial burocrático weberiano, na pesquisa-ação e na sociologia das profissões, em sua vertente racionalizadora.

\section{Materiais e métodos}

Do ponto de vista metodológico, tratou-se de um estudo de natureza qualitativa. Diante da realidade vigente, a opção pela pesquisa veio acompanhada da necessidade de transformação do processo de trabalho em odontologia, entendido como uma ação coletiva, e por isso se situou na perspectiva da pesquisa-ação (Franco, 2005).

Entre as técnicas de coleta das informações estavam a entrevista, o grupo focal, a oficina e a observação participante. A amostra constituiu-se de 350 usuários, 22 CD e 22 THD integrantes de 22 equipes de 12 centros de saúde. As entrevistas semiestruturadas, individuais e gravadas foram realizadas com os THD, referências técnicas dos distritos sanitários e os gerentes de centros de saúde, de maneira a compreender as imagens, ideias e percepções em relação às transformações operadas no processo de trabalho durante o desenvolvimento da pesquisa.

Utilizando um roteiro com questões semiestruturadas, o grupo focal reuniu os técnicos e CD para buscar informações nesse grupo acerca dos conceitos, impressões e concepções relativos a algumas circunstâncias que envolvem a 
prática do THD (Krueger, 1994; Minayo, 2007). Os encontros foram gravados. O grupo focal também foi utilizado para fazer uma reconstrução histórica da luta pela profissionalização do THD, no âmbito da SMSA-BH, a partir da escuta de cinco atores sociais que participaram de maneira ativa nesse processo.

A técnica de observação participante foi empregada no momento do grupo focal, visando a uma maior compreensão da fala e das ações dos sujeitos pesquisados para se entender o contexto e as vivências dos sujeitos estudados. Os pesquisadores observaram, coletaram e analisaram informações, reações e expressões corporais, e as falas dos sujeitos pesquisados, a partir de anotações livres (Minayo, 2007).

No que se refere à análise dos dados coletados, adotou-se a técnica de análise de conteúdo (Bardin, 1977), que, através de um conjunto de operações lógicas, busca as bases da compreensão da realidade por meio da linguagem. Possui como características metodológicas a objetividade, a sistematização e a inferência.

A análise dos dados se constituiu mediante a organização do material coletado nas entrevistas, grupos focais, oficinas e observação participante, através de várias leituras, buscando conhecer as suas características, singularidades, especificidades, posicionamentos cultural, econômico, político e social, e as opiniões que continham similaridade ou divergência. Em seguida a essa ordenação realizou-se a formulação de uma classificação inicial do conteúdo e a construção de matrizes, a fim de facilitar a interpretação do enunciado e a construção das 'categorias' de fragmentação do enunciado. Compreende-se que categorias são "rubricas ou classes as quais reúnem um grupo de elementos sob um título genérico, agrupamento esse efetuado em razão dos caracteres comuns desses elementos" (Bardin, 197, p. 117). Integraram-se, então, as categorias aos significados extraídos por meio das ferramentas de coleta de dados e do referencial teórico, através da proposição de inferências e da interpretação das mesmas (Bardin, 1977).

\section{Resultados e discussão}

Apreenderam-se quatro categorias: uma analítica e três empíricas. A modalidade de pesquisa-ação foi considerada uma categoria analítica, uma vez que resultou em achados para o contexto estudado, compreendendo-o e fundamentando-o em seus aspectos gerais e comuns. As categorias empíricas foram assim sintetizadas: fundamentação da prática e padronização das ações como maneira de garantir a legitimidade; valorização profissional e estratégias de resistência; e avanços e desafios. Estas categorias foram construídas com finalidade operacional, posteriormente ao trabalho de campo em suas especificidades e particularidades (Minayo, 2007). 
Para se trabalhar as categorias estruturou-se uma sequência considerando-se que a primeira categoria, 'modalidade de pesquisa-ação', desempenhou um importante papel no desenvolvimento da pesquisa, pois permitiu conhecer qualitativamente e, ao mesmo tempo, interagir e transformar o contexto estudado. Essa transformação dependeu da segunda categoria, que se refere à 'fundamentação da prática e padronização das ações', pois é necessário que o THD tenha uma direção em relação ao exercício profissional, que deve estar próximo ao seu entendimento quanto ao papel que exerce na sociedade. A terceira diz respeito à 'valorização profissional e as estratégias de resistência' utilizadas pelos profissionais, que estão diretamente relacionados ao seu reconhecimento no âmbito coletivo. E a quarta se relaciona aos 'avanços e desafios' presentes no exercício profissional do THD.

\section{A modalidade de pesquisa-ação}

A opção pela modalidade de pesquisa-ação se sustentou na possibilidade que ela constituiu para a reflexão coletiva sobre o processo de trabalho do THD. O que, de certa maneira, proporcionou um conhecimento mais abrangente do contexto dessas práticas e, consequentemente, viabilizou algumas mudanças na realidade vigente. Outra característica favorável quanto ao uso desse instrumento foi o avanço em relação a modelos rígidos, pois sua flexibilidade possibilitou a adoção de outras estratégias como pesquisador com duplo papel, de gestor e sujeito da investigação (Thiollent, 1997; 1985; Franco, 2005).

Essa pesquisa-ação, na perspectiva weberiana, configurou uma ação social com as quatro categorias de racionalidades interagindo de maneira complementar. A primeira delas, a 'racionalidade em finalidade', se relacionou com os objetivos próprios e ponderados da pesquisa, além da existência de uma expectativa quanto ao comportamento dos sujeitos envolvidos na investigação. A 'racionalidade em valor' se referiu ao valor intrínseco da ação. A 'racionalidade afetiva' foi permeada pela característica emocional presente na ação; e a 'racionalidade tradicional' se constituiu pela busca de padronização das ações que envolviam a prática profissional do THD.

A estrutura desta pesquisa evidencia os três níveis de uma ação social propostos por Weber (1982). O primeiro nível se constituiu com base no diagnóstico de que as práticas dos THD eram diferenciadas, não havia uma padronização, além da necessidade de aprimorar ou inserir a técnica do ART nessa prática. O segundo nível procurou compreender o sentido da padronização, bem como da inserção desta técnica. Por fim, o terceiro nível evidenciou as transformações operadas no processo de trabalho em odontologia através dessas ações. 
As mudanças proporcionadas no âmbito do trabalho foram realçadas por alguns THD:

(...) uma experiência bastante positiva, que deu e vai dar bons resultados, pois foi uma maneira de padronizar e melhorar o trabalho (...) pena que sempre falta material (...) não temos o ideal, é uma peleja (THD-5).

A THD, nesse depoimento, expressa a intrincada rede de limitações a que um profissional está sujeito, pois tem uma formação no âmbito de um cenário idealizado, distanciado da extensão e da complexidade do real. Aproxima-se do que Weber (1982) denomina 'tipo ideal', que, por ser um construto teórico, não é real e não representa a prescrição de um modelo. É uma abstração, portanto quase impossível de se tornar 'fato'. Diante dessas características relacionadas à perfeição, negligencia-se as adversidades que envolvem o processo produtivo em saúde. Não se pretende aqui desconsiderar as implicações que condições inadequadas de trabalho em odontologia podem proporcionar, mas ponderar que, diante de algumas dificuldades, deve-se adotar uma atitude cautelosa de forma a não transformar as questões individuais em universais. Ou, mesmo, entender que, diante da 'falta', algumas estratégias podem ser adotadas para viabilizar a resolutividade em saúde, a partir de ações pró-ativas. Contudo, a pesquisa-ação possibilitou verificar que essa vivência da 'carência' de materiais, equipamentos e instrumentais esteve presente na fala da maioria dos sujeitos da pesquisa.

A interação entre gestores e pesquisadores - THD-CD -, viabilizada pela modalidade da pesquisa-ação, favoreceu uma proximidade entre esses sujeitos, conforme a percepção de um dos pesquisados:

(...) eu imaginava pesquisa de outro jeito. Essa me pareceu diferente (...) ela também conseguiu aproximar toda a equipe de trabalho diário e também a gente com o pessoal responsável pela pesquisa (...) acho que isso é que permitiu as mudanças na pesquisa e no trabalho (THD 3).

A interação do grupo reforçou o compromisso de envolvimento dos interessados em transformar o processo de trabalho em saúde bucal. Essa proximidade também favoreceu momentos de discussão e retorno à equipe de trabalhadores, aos pesquisadores e gestores quanto às necessidades de mudanças e os resultados destas. Algumas intervenções por parte dos gestores explicitavam de forma nítida a estratégia de corresponsabilização utilizada: “(...) tem um lugar que queremos chegar (...) o caminho será construído por nós, cada um tem a contribuir (...)" (Gestor 4). Essa possibilidade de cooperação demonstra a importância de socialização desse tipo de pesquisa no campo da saúde, altamente mutável e complexo. Também justifica 
a pesquisa como oportunidade de avaliação que se constituiu como um norte para as reestruturações necessárias no âmbito do trabalho odontológico, traduzindo-se como uma forma de intervenção concreta nesse campo de ação, indo de encontro ao que Sommer e Arrick (2003) preconizam. Esses autores assinalam, como um dos aspectos inerentes a esse tipo de pesquisa, a viabilidade da mudança organizacional, essencialmente, quando os trabalhadores participam em todas as fases da pesquisa.

Os sujeitos pesquisados reconheceram a importância do diálogo para alterar as práticas odontológicas, o que foi realçado por um dos gestores:

(...) o contexto real é que está a nossa peleja, a nossa tentativa de fazer uma prática diferente. Uma prática coerente com os conhecimentos científicos (...) uma prática onde tenha como base o diálogo das equipes (Gestor 1).

A importância desse diálogo foi explicitada, também, pelos diversos atores presentes nesse estudo em vários momentos, nas oficinas, grupos focais e durante todo o processo de trabalho. Era a possibilidade de discussão, que partia dos múltiplos olhares e interpretações possíveis, sobre o desenvolvimento das ações e, ao mesmo tempo, de reflexão sobre elas, mediante situações concretas (Matus, 1997). Estas foram circunstanciadas por experiências individuais e coletivas diversas, com significados distintos para os diferentes atores. Pesquisar processos de trabalho subentende capturar particularidades ocultas, mas presentes naquela realidade específica. Socializar esse conhecimento é uma maneira de trazer à luz subsídios - que Paim e Almeida Filho (2000) denominam de 'meios de trabalho' - e de transformálos em objetos de ensino.

Compreendeu-se que os pressupostos característicos da pesquisa-ação permitiram evidenciar ações que emergiram de um coletivo: interações dialógicas, formação de acordos/negociações, busca pela superação de assimetrias de saber e poder, integração de processos de reflexão/pesquisa e formação, bem como as necessidades que surgem do processo.

\section{Fundamentação da prática e padronização das ações}

Na perspectiva weberiana, essa categoria alicerça a escolha por essa modalidade de pesquisa que pretendeu se aproximar da realidade vigente. De acordo com Weber (1982), a lógica da legitimidade é perpassada pela autoridade e pelo poder em uma relação de complementaridade. Essa vinculação marca a burocracia como uma ferramenta para a socialização das relações de poder. O poder constituído institucionaliza e legitima a autoridade que, orientada por um determinado saber, define quais as normas a serem cumpridas. Esse 
poder é ampliado quando esse saber se aproxima do conhecimento prático adquirido no serviço (Weber, 1982).

A importância da abordagem da prática profissional do THD em uma pesquisa foi assinalada por uma referência técnica de um distrito sanitário que a considerou como base:

(...) eu entendo a importância dessa pesquisa (...) ela conduzirá o trabalho do THD que ficou um pouco perdido. Nela a gente tá procurando fundamentar o dia-a-dia do serviço (...) padronizar as ações para criar protocolos (...) (Gestor 3).

Essa busca pela construção conjunta de rotinas foi um modo de trabalhar as normas que devem reger o trabalho em odontologia mediante a visão dos diversos trabalhadores. O perfil de competências instituído no 'Brasil Sorridente' (Brasil, 2004b) se situou como base para a instituição dos protocolos. A participação da equipe na padronização das ações, além de legitimar o poder de cada um deles como profissional, fortaleceu o poder da pesquisa, que, como prática científica, no entendimento dos sujeitos da pesquisa, poderia ser desempenhada apenas por determinadas autoridades. E, como já assinalado acima, os trabalhadores se sentiram incluídos neste poder de construção do conhecimento e do seu processo de trabalho, instituindo-se também como autoridade nesse processo capaz de ampliar a legitimidade das regras estabelecidas. Desta forma, a prática em odontologia passou a ser constituída pelos diversos saberes que a subsidiam, indo ao encontro do vínculo saber-poder-autoridade legitimada, firmado no referencial weberiano (Weber, 1999).

A padronização das ações também foi associada a um modo de legitimação da ação pelas THD:

(...) então, para legalizar o serviço, deveria haver mesmo uma padronização (...) nós ficávamos muito no ar, sem referência (...) o nosso trabalho tem que ser unificado (...) tenho certeza que aumentaríamos a nossa produção e atenderíamos muito mais pessoas. (THD-10).

(...) a proposta de a gente ter padrões para seguir nas nossas ações no serviço nos deixou mais seguras (...) autoconfiantes (...) (THD-7).

A concepção dessas THD se aproxima da de Abrantes et al. (2008), Lagioia et al. (2008), Bellotto e Linares (2008) e Melo (2010), que enfatizam a importância da instituição de diretrizes, leis e rotinas como uma estratégia de gestão. Esta assegura a sistematização do processo de trabalho como uma forma de organização e de favorecimento das ações da força de trabalho, uma vez que uniformiza as condutas, reduz as decisões individuais, privilegia a 
adequação das ações e serviços às de maior sustentação clínica, imprimindo-lhes a manutenção da capacidade técnica de melhor qualidade, menor custo, além de assegurar algum tipo de controle. Cabe, ainda, acrescentar que se evidenciou, no desenvolvimento da pesquisa, uma minimização das situações de conflito na equipe e, diante da possibilidade de continuidade e agilidade nas atribuições, uma otimização do tempo despendido para a ação odontológica. Todos esses efeitos, consequentemente, colaboraram para maior valorização não somente do TSB, mas de toda a equipe de saúde bucal. Weber (1999) e Likert (1975) ressaltam que um bom entrosamento entre a instituição e a força de trabalho é o meio mais adequado para se alcançar objetivos predefinidos e favorecer o desempenho da competência.

O tema competência tem sido discutido na literatura, de maneira mais detalhada, há pouco tempo. De acordo com Paiva e Melo (2008), esse conceito é distinto de qualificação, apoia-se na interdisciplinaridade e está em processo de construção. Na visão de Manfredi (1999), Bellotto e Linares (2008), Narchi (2010) e Rabelo e Oliveira (2010), o exercício de competência profissional demanda, além de conhecimento, capacidade reflexiva. Referese aos conceitos de capacidades cognitivas e emocionais associadas às habilidades e destrezas operacionais específicas a determinada prática laboral. Zarifian (2001), ao trabalhar a noção de competência com base em preceitos científicos, realça que ela se sustenta em três pilares básicos, a saber: responsabilidade e tomada de iniciativa; base de conhecimentos que viabiliza a consolidação e a transformação de práticas; e capacidade de liderar e mobilizar equipes em função de determinada ação.

Esses eixos traduzem os parâmetros nos quais a pesquisa se estruturou, visando à interlocução do ensino com a prática, agregando conhecimento aos saberes da experiência e da ação laboral, respeitadas as diferenças e individualidades de cada sujeito. O que, de acordo com os sujeitos da pesquisa, serviu de estímulo à capacidade da força de trabalho em formular, inovar e desenvolver o seu exercício profissional. Pois tinha-se o 'norte' de que competências se queriam instituir com a formalização e padronização dos procedimentos. Esta perspectiva propiciou adaptações às condições adversas, tão presentes no processo de trabalho em saúde.

A complexidade desse processo exige ações que privilegiem a participação coletiva e a gestão em saúde. Essa condição ficou evidente no comentário de uma referência técnica de um distrito:

(...) no início, não tinha noção do tanto que uma pesquisa poderia colaborar com a melhoria no ambiente de trabalho (...) a equipe toda, hoje, já convive com as dificuldades, que eles veem de outra maneira e não ficam mais paralisados. Eles mesmos se preocupam em resolvê-las. Para mim, essa tentativa de coordenar (...) acompanhar o trabalho através de rotinas ficou mais fácil. É engraçado, se pensarmos 
que as mesmas já existiam e que só com a pesquisa é que elas vieram à tona... talvez porque se tornou responsabilidade de todo o grupo (...) (Gestor 5).

A gestora acima sinaliza que a adoção de certas estratégias favoreceu não somente a gestão em saúde como todo o processo de atenção à saúde. Principalmente no que concerne ao princípio da corresponsabilização e ao modelo de gestão participativa, pois envolveu todos os atores sociais comprometidos com esse processo. De algum modo isso se tornou um estímulo para a capacidade da força de trabalho se tornar pró-ativa, em virtude dos desafios presentes na realidade laboral cotidiana.

Observou-se que a padronização dos procedimentos, desde que ligada aos preceitos éticos de responsabilização e de abertura institucional, e a participação da força de trabalho podem ser instrumentos de melhoria da qualidade das ações e dos serviços institucionais.

\section{Valorização profissional e estratégias de resistência}

O Estado, ao regulamentar a lei n. ${ }^{\circ} 11.889$ (Brasil, 2008), vem cumprir uma exigência para garantir o monopólio ocupacional, por meio de legislação específica, para o TSB e o ASC. De acordo com Machado (1996), na sociedade contemporânea, a valorização profissional está diretamente relacionada ao reconhecimento, monopólio, prestígio, autoridade cultural e autonomia. Dessa valorização depende a profissionalização, definida por Larson (1977) e Freidson (1988) como a confirmação de um 'status especial' para exercer uma atividade produtiva específica e controlar o acesso a ela, a qualidade e a capacitação para que se processe. Resulta de um processo coletivo de mobilidade social ascendente.

Na visão de Machado (1996), as profissões têm sofrido transformações caracterizadas como formas de proletarização, desprofissionalização e racionalização. A proletarização corresponde ao assalariamento dos profissionais liberais, denominados 'novos proletários', pois essa condição os aproxima da classe operária. A desprofissionalização se relaciona ao desgaste do monopólio do corpo de conhecimento, da autonomia e da credibilidade social. A racionalização, por seu turno, apresenta ligações profundas com os princípios burocráticos, que procuram racionalizar o processo de trabalho, adequando-o às normas administrativas e gerenciais. A predominância desses princípios, as mudanças na modalidade de remuneração e de organização do processo de trabalho substanciam alterações significativas na estrutura profissional antes vigente. Machado conclui que essas três vertentes assinalam a uniformização do processo de trabalho, os prejuízos no domínio do mesmo e nos privilégios antes existentes. 
A partir do objetivo a que essa pesquisa se propôs, optou-se por discutir a vertente da racionalização. Segundo Machado (1996) e Larson (1977), a racionalização ocorre mediante três características. A primeira se relaciona ao fortalecimento da divisão do trabalho, tanto no plano horizontal, por meio de qualificação profissional, com a especialização, como no vertical, que incumbe aos profissionais de menor escalão os afazeres rotineiros. Esta situação é evidenciada no contexto da pesquisa. No plano horizontal, segundo Durkheim (2008), relaciona-se à acumulação do saber, por intermédio da qual a formação específica é exigida para o exercício profissional do TSB, ao monopólio sobre essa esfera de trabalho e a um conjunto de preceitos éticos específicos. Estes utilizados como um instrumento de coesão e de controle da ação profissional. É com base nesses fatores que ocorre a divisão no plano vertical, distinguindo e hierarquizando as ocupações. As tarefas são divididas de acordo com o grau de formação do profissional, o que determina a submissão dos trabalhadores com menor grau de formação à supervisão dos que possuem maior grau.

Nesta pesquisa, no momento de reconstrução histórica da profissionalização do THD, duas afirmações deixaram claras a questão da percepção dos integrantes do grupo focal: “(...) a autonomia do THD (...) acaba sendo construída pelo CD (...) está tudo vinculado"(THD-2). Esta afirmação se baseou na condição de que toda ação do THD é realizada sob a supervisão do CD e, na concepção de Freidson (1971, 1998), é da autonomia que resulta o prestígio, o status e o poder nas ocupações. Situação que, segundo esses integrantes, provoca uma "baixa autoestima, refletindo na não organização como categoria profissional" (THD-4). Isso demonstra que, apesar de terem avançado no terreno cognitivo, ainda necessitam caminhar em direção às estratégias de autoorganização e de alcance de maior poder social. Entretanto, alguns THD assinalaram que a permanência de um maior número deles na pesquisa poderia estar associada a uma estratégia de demonstrar certa auto-nomia em relação aos CD. E, mesmo, como garantir um possível espaço de debates e de auto-organização sustentada no domínio de saberes e práticas, conforme Weber (1982) preconiza.

Diante dessas e de outras sinalizações apreendidas durante a pesquisa, percebe-se que o THD não se reconhece como sujeito da ação. E, devido às condições impostas para sua atuação profissional, se entende apenas como mais um componente submetido à estrutura organizacional. Autores como Santos e Faria (2008), Melo e Brant (2006) afirmam que esse tipo de dificuldade e/ou conflitos de autoridade é comum no campo da saúde, no qual se convive, atualmente, com situações de particularismos corporativistas como reserva de mercado. Santos e Faria (2008) recomendam reflexões sobre as competições e a viabilidade de solidariedade nas equipes de trabalho, de maneira que as lutas se transformem em negociações pactuadas, como provavelmente aconteceu no desenvolvimento desta pesquisa. Na concepção de Freidson 
(1988), esses enfrentamentos, geralmente, se constituem muito mais como forma de controle desses postos do que propriamente a partir de disputas referentes a conhecimento profissional específico.

A segunda característica se refere à necessidade de técnicos especializados para a constituição de protocolos para serviços de maior nível de complexidade. Entretanto, o objeto dessa pesquisa se originou da posição do grupo de coordenação: "Sentíamos necessidade de fortalecer o trabalho em equipe e de aumentar o número de atendimentos (...) como a qualidade desses" (THD-6). Esse posicionamento demandou a constituição da pesquisa no sentido de buscar evidências que corroborassem a proposição de ampliar e legitimar a área de atuação do THD. Para isso, fez-se necessária a construção de protocolos para a atuação do CD e do THD.

A terceira vertente da racionalização, conforme Larson (1977) e Machado (1996), relaciona-se ao aumento da carga de trabalho, o que interfere em direitos adquiridos, como horários para lanche e qualificação, ou na qualidade do serviço prestado. Esta condição também foi realçada pelos componentes do grupo focal quando assinalaram a inadequação da legislação vigente:

(...) Sete THD foram formadas na escola de saúde (...) em 2000, mas continuam como $\operatorname{ACD}(. .$.$) haveria perda de quinquênio, perda de férias, prêmio e algumas$ outras vantagens pessoais. Ela inicia um novo período probatório. Ela não consegue averbar o tempo de trabalho anterior (...) (THD-9).

Essas limitações também foram evidenciadas nos grupos focais com gestores, CD e THD. Os THD enfatizaram um acúmulo extraordinário de funções devido à instabilidade numérica da equipe, exacerbado no desenvolvimento da pesquisa. A pequena diferença salarial do THD em relação aos ACD diminui o estímulo de se qualificar para se tornar técnico. De acordo com Machado (1996), a qualificação confere autoridade cultural ao profissional e se constitui como o primeiro de dois componentes fundamentais para a organização de uma profissão. Tem uma forte associação à autoridade social.

O segundo componente para essa organização, de acordo com Machado (1996), é a autonomia. Este princípio, como já sinalizado nesse estudo, esteve presente na ação profissional do THD, apesar de seu trabalho assalariado. Esta relação de trabalho, na concepção de Moore (1970), pode ameaçar a autonomia laboral. Realça-se também que se pretendeu verificar as possibilidades junto à força de trabalho (THD) para que a adequação da conduta profissional às normas da gestão não ultrapasse um peso maior que o da competência técnica existente. Dessa maneira, buscou-se transformar o espaço laboral em um local de aprendizagem, cooperação, corresponsabilização e transparência de respeito mútuo. 


\section{Avanços e desafios}

Ao se falar de avanços e desafios, não se pode desconsiderar certa circularidade que envolve esses dois termos. Desafios, geralmente, dão origem aos avanços e estes, de algum modo, imprimem outros desafios. A opção pela pesquisa-ação se configurou como um desafio que deu origem ao avanço de trabalhar com esse tipo de pesquisa no campo da saúde. E, ao mesmo tempo, aproximou a pesquisa ao serviço, favorecendo a inserção do corpo de pesquisadores na realidade do processo de trabalho em odontologia, que trouxe à luz questões antes ofuscadas nesse ambiente. Baseando-se em Santos (1999), pode-se presumir que os desafios surgem das perplexidades oriundas de determinado contexto e, a partir deles, se constituem os avanços.

Vários desafios permearam o desenvolvimento da pesquisa, entre eles a falta de autonomia do THD, condições inadequadas de trabalho, sobrecarga de funções, equipe fragilizada, modelo de formação e prática clínica fragmentados, e usuários que se enquadrassem nos critérios de inclusão estabelecidos pela equipe de pesquisadores. Quase todos, de certa maneira, se transformaram em avanços durante o desenvolvimento ou no término da pesquisa. O maior deles foi a desistência de 11 equipes. Contudo, outras 11 equipes permaneceram por acreditar na viabilidade da pesquisa e no trabalho em equipe. O esforço dessa força de trabalho ficou demarcado, ao longo da pesquisa, por análises mais contextualizadas das diversas condições laborais e pela adoção de ações efetivas no enfrentamento dos desafios que se apresentaram. Essa motivação, muitas vezes, era justificada, com comentários como “(...) a minha relação com o dentista é de um completar o outro (...) é como se fosse a tampa e o balaio..." (THD-5). Este tipo de explanação demonstra a complementaridade e a interdependência existentes nesta relação de trabalho, norteada por intervenções técnicas e interação integral dos agentes em prol do cuidado, possibilitadora de intercâmbio de experiências e conhecimentos.

Peduzzi (1998) realça esta condição como fundamental para alimentar o trabalho em equipe, que reconhecidamente é dependente de um objetivo comum, sustentado por padrões individuais e coletivos que visem à maior integração entre os profissionais e as ações a serem desenvolvidas. Pressupõe-se que toda reorganização do processo de trabalho em saúde deve estar circunstanciada pela equipe, de maneira a favorecer decisões compartilhadas, baseadas em parâmetros objetivos focados no processo de trabalho e na capacidade de atender às necessidades dos usuários.

Nesta pesquisa buscou-se caminhar além da quantificação de atendimentos ao se acompanhar o desempenho das relações de trabalho entre os sujeitos da pesquisa. Desenhou-se uma abordagem de maior alcance, com continuidade e suporte para alcançar questões mais complexas, como as necessidades da equipe e da população envolvidas no processo da pesquisa, 
privilegiando uma discussão crítica em torno dessas necessidades. Esse tipo de postura facilita a construção do projeto comum.

Entretanto, essa construção parece ameaçada pelos ACD da rede, que, ao se sentirem excluídos na pesquisa, “(...) boicotam o serviço e a pesquisa veladamente..." (THD-11). Isto comprometeu o desenvolvimento adequado das ações e serviços. De acordo com a percepção dos CD e THD da pesquisa, as atribuições do ACD na rede SUS-BH se encontram cada vez mais ampliadas: “(..) mesmo se os ACD não boicotassem é impossível fazer a rotina e auxiliar o CD e o THD ao mesmo tempo..." (Gestor 5). Não se pode desconhecer também o acréscimo das atribuições de toda a equipe com a inserção da pesquisa. Seus desdobramentos influenciam diretamente as atividades profissionais das equipes, o monitoramento dos procedimentos realizados pelos ACD e THD ou, ainda, a supervisão dos gestores ou referências técnicas do cotidiano da unidade e de seus conflitos.

Em relação aos avanços alcançados, observou-se que o desafio de compartilhar as decisões motivou a corresponsabilização das ações realizadas entre os vários atores envolvidos. Entre os sujeitos que se mantiveram na pesquisa, as oportunidades de proposição, discussão e decisão tornaram-se similares, assegurando uma simetria de poder na equipe (Paim, 1992; Silva, 2005). Esta simetria às vezes era comprometida por afirmações como:

(...) sabia da necessidade do dentista me supervisionar, mas eu via que ela não queria assinar pelo meu trabalho (...) acompanhava (...) falava que tava bom (...) mas não queria assumir a responsabilidade (THD-8).

Esta afirmação demonstra uma confiança fragilizada do CD em relação ao THD.

Observou-se também certa debilidade na confiança por parte dos usuários, que não se sentiam à vontade para assinar o termo de consentimento livre e esclarecido. Sobre as estratégias utilizadas pelos usuários, um dos THD relata:

(...) Ah, a gente está fazendo uma pesquisa, você poderia assinar esse termo? Aí ele já fica de pé lá, pé cá. Ah, é, mas hoje eu estou com muita pressa, depois eu volto aqui pra poder assinar, tá? (THD-8).

Esta situação talvez explicite também uma relação de confiança fragilizada, na qual o usuário não se percebe como cidadão de direito e nem como sujeito da ação. O processo de atenção à saúde parece ter a relação de trabalho consolidada apenas no interior da equipe, apesar do controle social ser um dos princípios organizativos do SUS. Autores como Peduzzi (1998) e Crevelim e Peduzzi (2005) ressaltam essa dificuldade de inserção dos usuários como 'partícipes do trabalho em equipe' ou de pró-atividade em 
relação às suas condições de vida e de saúde. Somente dessa forma o processo de atenção à saúde terá um objeto comum e será voltado para a real necessidade dos usuários.

Todavia, reconhece-se que qualquer mudança nesse processo é lenta, e o imediatismo, geralmente pertinente ao campo da saúde, induz alguns sujeitos da pesquisa a assumir esse tipo de posição: “(...) eu não quero continuar na pesquisa, pois tenho que produzir, é uma exigência enorme da coordenação (...) minha THD é muito lenta, vou acabar perdendo tempo (...)" (CD-6). Esse depoimento demonstra certa acomodação do profissional, que, ao tomar conhecimento dos benefícios, poderia assumir uma postura de superação de uma imposição que concebe o processo de trabalho em saúde com base apenas em produto numérico. Negligenciando o impacto que essa condição pode trazer em termos da situação de saúde da população, produz-se muito, mas se controla minimamente o processo saúde-doença, principalmente se tiver como parâmetro a densidade populacional e o acúmulo de necessidades.

Esse tipo de posicionamento vai na contramão do que Narvai (2006) salienta quanto à necessidade de se viabilizar o acesso de todos aos cuidados odontológicos, caracteristicamente um direito humano. Não basta, então, reproduzir práticas sem propiciar estratégias de reflexão sobre elas mesmas e sobre os cuidados inerentes às relações sociais constituídas entre todos os atores participantes do processo. Cabe lembrar que essas relações podem ser fortalecidas por metodologias que busquem se apropriar de uma abordagem de equipe, já assinalada; do fazer em saúde baseado em processos de reflexão e do ambiente de trabalho como um locus privilegiado de ensino-aprendizagem. Esta é uma das estratégias para se ultrapassar o enraizamento do modelo hegemônico assistencial sem procurar avançar para um modelo que vise realmente ao processo de atenção à saúde (Almeida Filho e Paim, 1997; Narvai, 2000).

A inserção de novas práticas no processo de atenção odontológica demanda, entre outras exigências legais e científicas, a qualificação da equipe de saúde bucal, a ampliação do acesso da população a esse processo, a prevenção de doenças bucais e uma melhor relação custo-benefício. Diante desse contexto e na perspectiva de inserir a ART como uma nova prática na realidade cotidiana laboral do THD, estruturaram-se módulos de qualificação teóricos e um acompanhamento mais próximo do $\mathrm{CD}$.

A técnica ART é baseada na mínima intervenção e máxima preservação das estruturas dentárias, sustentando-se como uma estratégia de promoção de saúde. Representa uma técnica de segurança para o tratamento da doença cárie no âmbito da saúde coletiva, minimizando a demanda reprimida e ampliando a cobertura. De acordo com Lima, Saliba e Moimaz (2008) em uma pesquisa realizada na África do Sul, observou-se que as restaurações 
de ART custam a metade do valor das convencionais. Os autores acrescentam como qualidade da técnica a ausência de ruído e vibração, o que torna o atendimento clínico mais agradável ao paciente.

Um THD relata a experiência de qualificação teórica e prática quanto a essa técnica da seguinte forma:

(...) o curso que fizemos foi muito bom, mas a minha insegurança era tamanha no início (...) eu não me sentia nem um pouquinho preparada, mas a doutora me ajudou tanto que hoje, além dela elogiar, vejo que eu sei fazer (THD-4).

Fica evidente o reconhecimento da teoria para os que pretendem começar a usar a técnica, mas também a fundamentalidade da prática para viabilizar a segurança do 'fazer'. Um dos CD pondera que: “Só com o término da pesquisa que vi que o potencial da minha THD é mal explorado" (CD-7). Este comentário pode estar ligado à dificuldade, assinalada por Araújo e Rocha (2007), da categoria de nível superior reconhecer a capacidade do nível médio, configurando 'relações de poder hierarquizadas'. Mas reforça a condição de que essas transformações envolvem um processo de médio a longo prazo e uma relação de confiança do THD com a técnica e, ao mesmo tempo, entre a equipe, necessários ao sucesso clínico. Este, na visão de Bresciani (2006), Vieira et al. (2006) e Oliveira, Bittencourt e Oliveira (2009), se vincula diretamente ao treinamento, domínio e experiência do ART, uma vez que associam as falhas clínicas desta técnica à habilidade e desempenho de quem a está aplicando.

Em relação ao trabalho do CD, um dos THD apontou:

Eu me pergunto como eles podem ser contra (...) como eles vão ensinar. Pois eu fico observando (...) a maioria dos dentistas não fazem ART (...) eles preferem usar motor e restaurar mesmo com amálgama e resina (THD-10).

Essa crítica parece plausível quando ainda se defronta com uma prática em saúde bucal baseada em um modelo curativo e procedimentos convencionais, mesmo reconhecendo que o controle da doença cárie vai além de um procedimento clínico. A influência dessa técnica neste controle tem sido realçada por autores como Bresciani (2006), Vieira et al. (2006), Lima, Saliba e Moimaz (2008), Garbin, Sundfeld e Santos (2008) e Oliveira, Bittencourt e Oliveira (2009), ao afirmarem que, mediante uma vedação adequada com a ART, o processo de desmineralização pode ser paralisado, devido as suas qualidades de adesão e, no caso do cimento de ionômero de vidro, anticariogênicas, ao liberar flúor. Contudo, ressaltam que deve ser utilizada em áreas de baixa tensão ou cavidades de uma superfície, devido as suas frágeis propriedades mecânicas, semelhantes as da dentina. 
Em síntese, diante dos dois últimos depoimentos dos sujeitos da pesquisa, observou-se que os THD, apesar de devidamente treinados e calibrados além de um cuidadoso acompanhamento do $\mathrm{CD}$, somente adquiriram confiança para a realização da técnica e um maior sucesso na retenção do material restaurador após certo tempo de experiência. Quanto às falhas, CD e THD assinalaram que as falhas mais comuns se relacionavam ao desgaste, à perda parcial ou total do material restaurador e à lesão cariosa na margem da restauração. Este último problema foi minimizado com a pressão do dedo sobre o material, pois ampliou a sua zona de contato com o dente. Nesta perspectiva, existe uma coerência no que se encontrou na pesquisa, referente ao ART, com o que a literatura preconiza. Assim, entende-se a viabilidade do uso do ART pelo THD na saúde pública. Observou-se, ainda, que para o THD vencer a sua insegurança foi importante a prática em equipe de característica responsável e colaborativa. Característica essencial que, na concepção de Rocha e Araújo (2009), é um tanto limitada no processo de formação do cirurgião-dentista e, consequentemente, no exercício da odontologia.

Reconhece-se que ter a noção do conjunto de valores que permeiam as concepções e práticas relacionadas ao processo de atenção à saúde bucal se constitui como uma das possibilidades de se retratar a dinâmica do serviço. Isto é favorecido também pela inserção da pesquisa no ambiente do trabalho. Esta situação, de algum modo, beneficia a integração entre os profissionais e as intervenções, aproximando dos critérios assinalados por Peduzzi (2001). Estes se baseiam numa força de trabalho cujas ações sejam articuladas e sustentadas em estratégias de comunicação, no respeito às diferentes técnicas de abordagem e na autonomia específica de cada um dos integrantes da equipe. Táticas que otimizaram o processo de atenção odontológica, pois mais de $55 \%$ dos usuários tiveram os problemas resolvidos em, no máximo, duas sessões, o que de certa maneira demarcou o grau de profissionalização do THD. Segundo Larson (1977), o processo de profissionalização está vinculado ao que a ocupação tem a ofertar, e no caso dessa pesquisa, um menor número de sessões para a conclusão do tratamento resultou na ampliação do acesso e no aumento da cobertura.

Nessa perspectiva, cabe apresentar outro avanço proporcionado por esse estudo, de acordo com um THD: “(...) essa pesquisa é muito importante para definir a nossa posição, o nosso lugar dentro da equipe e do centro de saúde" (THD-1). Essa definição é a possibilidade desse profissional reconhecer a sua posição como integrante de uma equipe de saúde, tornando-se sujeito de ação. Também permite demarcar a sua organização profissional, que, para Larson (1977), depende da socialização do que a profissão tem a oferecer. Esse tipo de espaço era fundamental para uma equipe não acostumada a parar e refletir e que, diante dessa abertura, se tornou autora e condutora das ações que iriam ser contempladas no processo de atenção à saúde bucal. 
Ressalte-se que a modalidade da pesquisa-ação tornou possível a discussão e a reflexão sobre o estabelecimento de rotinas vivenciado de maneira pró-ativa e solidária com a inserção delas na prática clínica. Seguindo a concepção de Starr (1991), entende-se que a institucionalização e a legitimidade das ações laborais do THD estão asseguradas pelos acordos consensuais estabelecidos no âmbito da equipe de saúde bucal. Esses acordos é que legitimam a autoridade profissional do THD.

No intuito de retomar o significado desta pesquisa, extraíram-se os seguintes depoimentos:

Eu vejo essa pesquisa [como] uma reconquista institucional e da categoria (...) tava passando da hora dessa reciclagem que tá acontecendo na pesquisa (...) tudo no mundo da saúde vai evoluindo e nós estamos ficando um pouco para trás (...) a profissão de THD chegou ao ponto de frustração (CD-3).

(...) dessa pesquisa para cá, eu fui mais bem aproveitada (...) houve um crescimento

(...) um apoderamento em todas as questões (CD-1).

Depoimentos desta natureza demonstram o lugar que a pesquisa ocupou para o fortalecimento da profissionalização do THD e, deste, como um sujeito da ação. Também demarcam o benefício de estratégias como essa para envolver a força de trabalho em modalidades de qualificação baseada na concepção de aprendizagem social e voltada para a esfera pública.

\section{Considerações finais}

O desenvolvimento da pesquisa favoreceu a experiência de se trabalhar com uma modalidade de pesquisa ainda pouco explorada no campo da odontologia. O seu objeto procurou resguardar a ação profissional do THD, sistematizando-a a partir de subsídios teóricos e práticos, de maneira a gerar credibilidade e garantir a qualidade dos serviços prestados. E, dessa maneira, afiançar um bom desempenho no processo de atenção odontológica, conferindo-lhe 'confiança pública' e garantindo melhores condições de saúde ao usuário do SUS. O método adotado possibilitou compreender as práticas desenvolvidas pela equipe de saúde e as estratégias adotadas no sentido de reinventá-las.

Além desse desafio vinculado ao THD, outros se fizeram presentes, como a permanência no processo de pesquisa, algumas vezes entendida como mais uma sobrecarga de trabalho. A manutenção de 11 equipes foi justificada pela importância do trabalho em equipe e pela possibilidade de ampliação da autonomia e do exercício de novas habilidades como a prática da ART pelo THD. Essas equipes contribuíram, sobremaneira, para um salto de qualidade na 
reorganização das ações e serviços, a partir da corresponsabilização dos CD e THD. Esta situação demonstra a importância de instrumentos que viabilizem espaços de reflexão e construção para a legitimação e credibilidade de novas evidências clínicas na prática em saúde, baseadas em uma relação de confiança, usuário-centrado, na ampliação de cobertura e na qualidade do cuidado.

Em síntese, a história de luta e resistência dessa categoria profissional, tantas vezes silenciada, ganhou voz, ao se colocar como foco desta pesquisa. Sua importância é reconhecida no processo de atenção à saúde bucal como um todo e não simplesmente associada ao aumento na produtividade, diminuição do estresse e fadiga do CD. Ressalte-se que o compromisso primeiro de toda equipe de saúde bucal é tornar as ações em saúde um direito básico acessível a todos os cidadãos.

\section{Notas}

1 Cirurgiã-dentista da Secretaria Municipal de Saúde de Belo Horizonte, Minas Gerais, Brasil. Mestre em Educação pela Pontifícia Universidade Católica de Minas Gerais. <elianamariasa@yahoo.com.br>

Correspondência: Escola de Saúde Pública do Estado de Minas Gerais, Avenida Augusto de Lima, 2061, Barro Preto, CEP 30190-002, Belo Horizonte, Minas Gerais, Brasil.

2 Superintendente de Pesquisa da Escola de Saúde Pública do Estado de Minas Gerais, Minas Gerais, Brasil. Doutora em Ciências da Saúde pela Fundação Oswaldo Cruz. $<$ marilenebmelo@gmail.com>.

3 Cirurgião-dentista da Secretaria Municipal de Saúde de Belo Horizonte, Minas Gerais, Brasil. Especialista em Gestão de Unidade Básica de Saúde pela Escola de Saúde Pública de Minas Gerais. <carlosten@globo.com>

4 Cirurgião-dentista da Secretaria Municipal de Saúde de Belo Horizonte, Minas Gerais, Brasil. Especialista em Saúde Coletiva pela Associação Brasileira de Odontologia. <lucasazeveira@yahoo.com.br>

${ }^{5}$ Cirurgiã-dentista da Secretaria Municipal de Saúde de Belo Horizonte, Minas Gerais, Brasil. Especialista em Saúde Coletiva pela Escola de Saúde Pública de Minas Gerais. $<$ noreply@quepasa.com>

6 Assessor do Secretário de Saúde do Estado de Minas Gerais, Minas Gerais, Brasil. Especialista em Periodontia e Prótese pela Faculdade de Odontologia de Bauru. $<$ onofram@yahoo.com.br>

7 Cirurgião-dentista da Secretaria Municipal de Saúde de Belo Horizonte, Minas Gerais, Brasil. Mestre em Clínica Odontológica pela Universidade Federal de Minas Gerais. $<$ rubens@joinnet.com.br> 
8 Cirurgiã-dentista da Secretaria Municipal de Saúde de Belo Horizonte, Minas Gerais, Brasil. Especialista em Gestão em Saúde pela Pontifícia Universidade Católica de Minas Gerais.<dulcehag@yahoo.com.br>

\section{Referências}

ABRANTES, Patrícia M. et al. A qualidade da prescrição de antimicrobianos em ambulatórios públicos da Secretaria Municipal de Saúde de Belo Horizonte. Ciência \& Saúde Coletiva, Rio de Janeiro, v. 13, supl. 1, p. 711720, abr., 2008.

ARAÚJO, Marize B. S.; ROCHA, Paulo. M. Trabalho em equipe: um desafio para a consolidação da estratégia de saúde da família. Ciência \& Saúde Coletiva, Rio de Janeiro, v. 12, n. 2, p. 455-464, mar./abr., 2007.

BARDIN, Laurence. Análise de conteúdo. Tradução de Luís Antero Reto e Augusto Pinheiro. Lisboa: Edições 70, 1977.

BELLOTTO, Maria L.; LINARES, Imma P. Las competencias profesionales del nutricionista deportivo. Revista de Nutrição, Campinas, v. 21, n. 6, p. 633-646, nov./dez., 2008.

BRASIL. Ministério da Saúde. Perfil de competências profissionais do técnico em higiene dental e do auxiliar de consultório dentário - Ministério da Saúde. Brasília, DF: Ministério da Saúde, 2004a. 24p. - (Série A. Normas e Manuais Técnicos).

Ministério da Saúde. Secretaria de Atenção à Saúde. Departamento de Atenção Básica. Coordenação Nacional de Saúde Bucal. Diretrizes da politica nacional de saúde bucal. Brasília: Ministério da Saúde, 2004b. Disponível em: http:/bvsms.saude.gov.br/ bvs/publicacoes/política_nacional_brasil_ sorridente.pdf. Acesso em: 10 maio 2009.

Ministério da Saúde. Lei n. ${ }^{\circ} 11.889$, de 24 de dezembro de 2008. Regulamenta o exercício das profissões de técnico em saúde bucal (TSB) e de auxiliar em saúde bucal (ASB). Diário Oficial da União, $26 \mathrm{dez}$. 2008. Disponível em: www010.dataprev. gov.br/sislex/paginas/42/2008/11889.htm. Acesso em: 12 maio 2009.

BRESCIANI, Eduardo. Clinical trials with Atraumatic Restorative Treatment (ART) in deciduos and permanent teeth. Journal of Applied Oral Science, v. 14, n. esp., p. 14-19, 2006.

CREVELIM, Maria A.; PEDUZZI, Marina. Participação da comunidade na equipe de saúde da família: é possível estabelecer um projeto comum entre trabalhadores e usuários? Ciência \& Saúde Coletiva, Rio de Janeiro, v. 10, n. 2, p. 323-331, abr./jun. 2005.

DURKHEIM, Émile. Da divisão do trabalho social. Tradução de Eduardo Brandão. 2. ed. São Paulo: Martins Fontes, 2008

FRANCO, Maria. A. S. Pedagogia da pesquisa-ação. Revista da Educação e Pesquisa, São Paulo, v. 31, n. 3, p. 483-502, set., 2005. Disponível em: <www.scielo.br $>$. Acesso em: 3 dez. 2005.

FREIDSON, Eliot. Profession of medicine: a study of the sociology of applied knowledge. New York: Dodd, Mead, 1971.

FREIDSON, Eliot. Renascimento do profissionalismo: teoria, profecia e política. Tradução de Celso Mauro Paciornik. São Paulo: Edusp, 1988.

GARBIN, Cléa A. S.; SUNDFELD, Renato H.; SANTOS, Karina T. et al. Aspectos atuais 
do tratamento restaurador atraumático. Revista da Faculdade de Odontologia, Passo Fundo, v. 13, n. 1, p. 25-29, jan./abr., 2008.

KRUEGER, Richard. A. Focus group: a practical guide for applied research. 2. ed. Thousand Oaks: Sage-USA, 1994.

LAGIOIA, Umbelina C. T. et al. A gestão por processos gera melhoria de qualidade e redução de custos: o caso da unidade de ortopedia e traumatologia do hospital das clínicas da Universidade Federal de Pernambuco. Revista Contabilidade \& Finanças, São Paulo, v. 19, n. 48, dez., 2008. Disponível em: <www.scielo.br/scielo.phpscript =sci_arttext\&pid=S151970772008000300007 $\& \operatorname{lng}=$ pt\&nrm=iso $>$. Acesso em: 31 mar. 2010.

LARSON, Magali S. The rise of profissionalism. Berkeley-Ca: University of California, 1977.

LIKERT, Rensis. A. Organização humana. São Paulo: Atlas, 1975.

LIMA, Daniela C.; SALIBA, Nemre A.; MOIMAZ, Suzely A. S. Tratamento restaurador atraumático e sua utilização em saúde pública. Revista Gaúcha de Odontologia, Porto Alegre, v. 56, n. 1, p. 75-79, jan./mar., 2008.

NARVAI, Paulo C. Saúde bucal coletiva: caminhos da odontologia sanitária à bucalidade. Revista de Saúde Pública, São Paulo, v. 40, n. esp., p.141-147, ago., 2006.

MACHADO, Maria H. Os médicos e sua prática profissional: as metamorfoses de uma profissão. 1996. 215f. Tese (Doutorado em Sociologia) - Instituto Universitário de Pesquisas do Rio de Janeiro, 1996.

MANFREDI, Silvia. M. Trabalho, qualificação e competência profissional: das dimensões conceituais e políticas. Educação e Sociedade, Campinas, v. 19, n. 64, p. 13-49, jul./set. 1999.

MATUS, Carlos. Politica, planejamento \& governo. Brasília: Ipea, 1997.

MELO, Marilene. B. O processo de trabalho e o protocolo na atenção odontológica. Prêmio
Sinog de Odontologia: trabalhos premiados 2005 a 2009. São Paulo: Sindicato Nacional das Empresas de Odontologia de Grupo (Sinog), p. 57-69, 2010.

MELO, Marilene B.; BRANT, Luiz C. Ato médico: perda da autoridade, poder e resistência. Psicologia Ciência e Profissão, Brasília. v. 25, n. 1, p. 14-29, mar. 2005.

MINAYO, Maria C. S. O desafio do conhecimento: pesquisa qualitativa em saúde. 10. ed. São Paulo: Hucitec, 2007.

MOORE, Wilbert. E. The professions: roles and rules. New York: Russell Sage Foundation, 1970.

NARCHI, Nádia. Z. Análise do exercício de competências dos não médicos para atenção à maternidade. Saúde e Sociedade, São Paulo, v. 19, n. 1, p. 147-158, jan./mar. 2010.

OLIVEIRA, Marcelo T.; BITTENCOURT, Sandra T.; OLIVEIRA, Marilin D. S. Avaliação clínica do desempenho de TRA (tratamento restaurador atraumático) associado a um agente químico de remoção de cárie. Revista Odonto Ciência, Porto Alegre, v. 24, n. 2, p. 190-193, abr./jun. 2009.

PEDUZZI, Marina. Equipe multiprofissional de saúde: a interface entre trabalho e interação. 1999. 154f. Tese (Doutorado em Ciências Médicas) - Faculdade de Ciências Médicas, Universidade Estadual de Campinas, Campinas, 1999.

Equipe multiprofissional de saúde: conceito e tipologia. Revista de Saúde Pública, São Paulo, v. 1, n. 35, p. 103-109, jan./fev., 2001.

PAIM, Jairnilson S. Collective health and the challenges of practice. In: PAHO. The crisis of public health: reflections for the debate. Washington: PAHO, 1992, p. 136-150. (Scientific Publication, 540).

PAIM, Jairnilson S.; ALMEIDA, Naomar. F. A crise da saúde pública e a utopia da saúde coletiva. Salvador: Casa da Qualidade Editora, 2000. 
PAIVA, Kely C. M.; MELO, Marlene C. O. L. Competências, gestão de competências e profissões: perspectivas de pesquisas. Revista de Administração Contemporânea, Curitiba, vol. 12, n. 2, p. 339-368, abr./maio, 2008.

RABELO, Leila R.; OLIVEIRA, D. L. Percepções de enfermeiras obstétricas sobre sua competência na atenção ao parto normal hospitalar. Revista da Escola de Enfermagem, São Paulo, v. 44, n. 1, p. 213-220, jan./mar., 2010.

ROCHA, Evelin. C. A; ARAUJO, M. A. D. Condições de trabalho das equipes de saúde bucal no Programa Saúde da Família: o caso do distrito sanitário norte em Natal, RN. Revista de Administração Pública, Rio de Janeiro, v. 43, n. 2, abr. 2009. Disponível em: <www.scielo.br/scielo.php?script $=$ sci_ arttext\&pid=S003476122009000200010\&lng $=$ pt\&nrm $=$ iso $>$. Acesso em: 20 abr. 2010.

SANTOS, Boaventura S. Pela mão de Alice: o social e o político na pós-modernidade. 6. ed. São Paulo: Cortez, 1999.

SANTOS, Luiz A. C.; FARIA, Lina. As ocupações supostamente subalternas: o exemplo da enfermagem brasileira. Saúde e Sociedade, São Paulo, v. 17, n. 2, p. 35-44, maio/ago., 2008.

MINAS GERAIS. Secretaria Municipal de Saúde de Belo Horizonte. BH-Vida: Saúde integral. Diretrizes para o avanço e articulação do processo assistencial na SMSA para o período 2003-2004. Documento de circulação interna, mar. 2003. 17 p.

Secretaria Municipal de Saúde. Plano municipal de saúde de Belo Horizonte: 2005-2008. Belo Horizonte: SMS-BH, 2005. SILVA, Iêda Z. Q. J; A. O trabalho em equipe no PSF: investigando a articulação técnica e a interação entre os profissionais. Tradução de Leni Bonfim. Interface - Comunicação, Saúde e Educação, Botucatu, v. 9 n. 16, p. 25-38, set./fev. 2005.

SOMMER, Robert; AMICK Terrence. Pesquisa-ação: ligando pesquisa à mudança organizacional (Série: Planejamento de Pesquisa nas Ciências Sociais, n. 04). Tradução de Hartmut Günter. Brasília, DF: Laboratório de Psicologia Ambiental, UNB, 2003. Originalmente publicado em 1984.

STARR, Paul. La transformación social de la medicina en los Estados Unidos de América. Mexico: Fondo de Cultura Economica, 1991.

THIOLLENT, Michel. Metodologia da pesquisa-ação, 14. ed. São Paulo: Cortez, 1985.

Pesquisa-ação nas organizações.

São Paulo: Atlas, 1997.

VIEIRA, Ana. L. F. et al. Evaluation of glass ionomer sealants placed according to the ART approach in a community with high caries experience: 1-year follow-up. Journal of Applied Oral Science, Bauru, v. 14, n. 4 , p. 270-275, ago., 2006.

WEBER, Max. Ensaios de Sociologia. 5. ed. Rio de Janeiro: Zahar Editores, p. 229-282, 1982.

Economia e Sociedade. Brasília, DF:

Editora da Universidade de Brasília, 1999. vol. 1, cap. 1, p. 7-43.

ZARIFIAN, Philippe. Objetivo competência: por uma nova lógica. Tradução de Maria Helena C. V. Trylinski. São Paulo: Atlas, 2001.

Recebido em 25/01/2010

Aprovado em 05/07/2010 